\title{
A Review of Bioeconomic Modelling of Habitat-Fisheries Interactions
}

\author{
Naomi S. Foley, ${ }^{1}$ Claire W. Armstrong, ${ }^{1}$ Viktoria Kahui, ${ }^{2}$ Eirik Mikkelsen, ${ }^{3}$ and Siv Reithe ${ }^{1}$ \\ ${ }^{1}$ Norwegian College of Fishery Science, University of Tromsø, 9037 Tromsø, Norway \\ ${ }^{2}$ Department of Economics, University of Otago, Dunedin 9016, New Zealand \\ ${ }^{3}$ Northern Research Institute, NORUT, Tromsø, 9294 Tromsø, Norway \\ Correspondence should be addressed to Naomi S. Foley, naomifoley@gmail.com
}

Received 15 August 2011; Revised 14 October 2011; Accepted 15 October 2011

Academic Editor: Panos V. Petrakis

Copyright (c) 2012 Naomi S. Foley et al. This is an open access article distributed under the Creative Commons Attribution License, which permits unrestricted use, distribution, and reproduction in any medium, provided the original work is properly cited.

This paper reviews the bioeconomic literature on habitat-fisheries connections. Many such connections have been explored in the bioeconomic literature; however, missing from the literature is an analysis merging the potential influences of habitat on both fish stocks and fisheries into one general, overarching theoretical model. We attempt to clarify the nature of linkages between the function of habitats and the economic activities they support. More specifically, we identify theoretically the ways that habitat may enter the standard Gordon-Schaefer model, and nest these interactions in the general model. Habitat influences are defined as either biophysical or bioeconomic. Biophysical effects relate to the functional role of habitat in the growth of the fish stock and may be either essential or facultative to the species. Bioeconomic interactions relate to the effect of habitat on fisheries and can be shown through either the harvest function or the profit function. We review how habitat loss can affect stock, effort, and harvest under open access and maximum economic yield managed fisheries.

\section{Introduction}

The connection between marine habitats and fisheries is increasingly being made in policy recommendations for fisheries management, both with regard to inclusion of essential fish habitat and in overall ecosystem management approaches. For instance, European directives such as the Marine Strategy Framework Directive and the Habitats Directive, as well as the Magnuson Stevens Act in the US, seek to protect marine habitats and ecosystems. Habitat loss has been suggested as one of many reasons for declining fish stocks [1].

Biological research indicates that loss or changes in habitat affect species, including those of commercial interest [2]. Bottom trawling has received much attention and has been described as the marine equivalent to forest clear cutting, acting as a major threat to biological diversity and economic sustainability [3]. The damage to habitats may reduce future harvests through the reduction or loss of spawning, nursery, or refuge grounds for commercial species. Fish habitats include mangroves, saltmarshes, and tropical coral reefs, which are also threatened by coastal development [4].
In recent years, ecologists have also drawn attention to deep sea habitats, such as cold water corals.

There is a literature on the connections between habitats and commercial fish stocks and the effects of fishing upon ocean habitats (see Armstrong and Falk-Petersen [5] for an overview). Although it is clear that destructive fishing practices create externalities for other vessels and impose user costs on the fishers themselves (there is a small literature on the positive effect of trawling on certain habitats, at least in the short term. Shephard et al. [6] and Hiddink et al. [7] report that moderate trawl disturbance on sand habitats may enhance the feeding and thus the growth rate of certain species in these habitats), economic consequences of a change or loss in habitat are poorly understood [5]. Aspects of habitat connections have been included in some of the bioeconomic literature, but it is slim and not very cohesive. Knowler [8] and Barbier [9] present reviews of selected bioeconomic studies of environmental effects. Missing from the literature is a general analysis merging the potential influences of habitat on both fish stocks and fisheries.

In this paper we attempt to clarify the nature of linkages between the function of habitats and the economic activities 


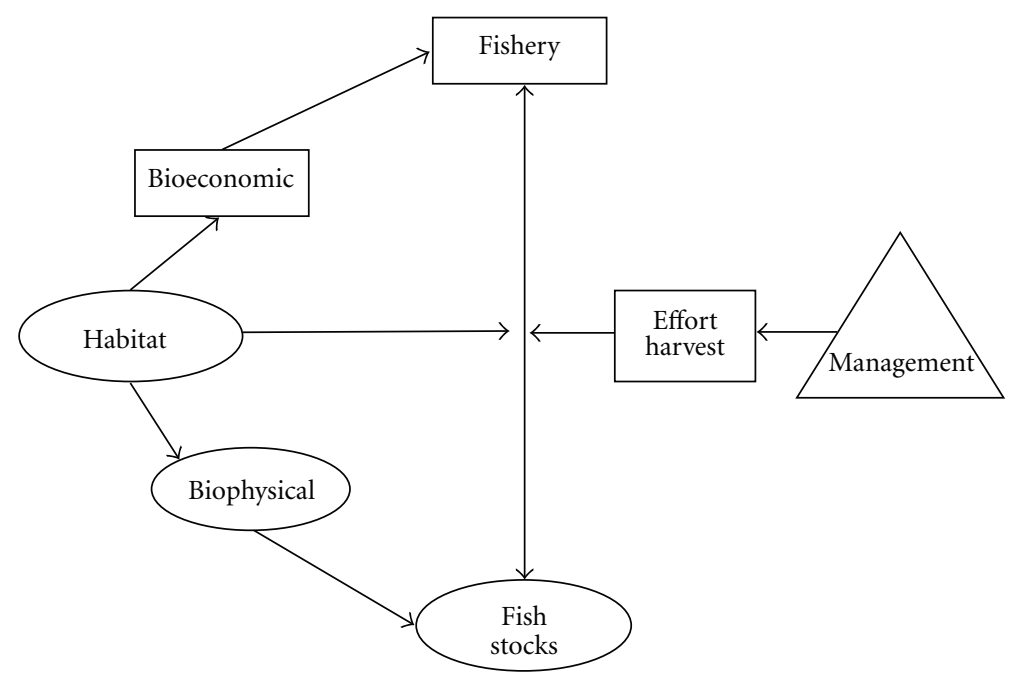

FIGURE 1: Habitat interactions. Interactions drawn in the ovals represent biological entities associated with habitat, while squares and triangles are human behavioural entities.

they support. We identify and review fish-habitat interactions in the literature and nest a number of different models under one overarching general model, which provides a theoretical foundation for habitat interactions. Specifically, four habitat relations are examined through the bioeconomic parameters; habitat can be (1) facultative, (2) essential, have (3) a positive effect on the catchability, or finally (4) a potential price increasing effect. The former two are grouped under biophysical effects while the latter two under bioeconomic effects. We analyse the effects of changes in habitat size or quality on steady-state effort, stock, yield, and profits for both open access and maximum economic yield (MEY) fisheries by looking at the comparative statics of each model.

The remainder of this paper is organised as follows: the next section presents a review of habitat interactions and the bioeconomic literature related to these interactions. Section 3 presents the general model nesting all habitat effects and then the specific models. This is followed by a comparative static analysis on the effects of a reduced habitat in Section 4. Finally, the paper concludes with a general discussion and recommendations for further research.

\section{Habitat Interactions}

Habitat dimensions can include habitat size or habitat quality. For studies involving nonrenewable habitats such as cold-water corals, size may be the most suitable dimension, whereas quality measures may be more appropriate when habitat gradually deteriorates as fishing intensity increases.

Habitat size or quality can influence commercial stocks or fisheries upon these stocks as illustrated in Figure 1. Biophysical connections relate to the natural effect of the habitat on the growth of a stock, and even symbiotic relations between the fish and the habitat may exist. Stock growth may be positively affected by habitat through the provision of spawning, nursery, refuge, or feeding grounds. Bioeconomic connections influence the fishery costs and prices. Some habitats may encourage the concentration of certain species leading to increased catchability thus lowering harvesting costs or increasing harvest for a given level of effort (see, e.g., Armstrong and van den Hove [10]). It is also possible for fisheries that preserve a habitat to obtain a price premium in the market via, for instance, ecolabeling, thus increasing income.

An example of habitat with reported biophysical and bioeconomic effects are cold-water corals. Cold-water coral sites appear to act as habitat for many species [11]. However, little is understood of the functional relationships between species that aggregate around the corals and the importance of corals as a fish habitat. Thus, corals may play an essential role for the life history of some species or may simply be a preferred location. There is also evidence that corals have bioeconomic effects in terms of reduced costs and effort. Fishermen observe higher concentrations of fish in coral areas, leading to higher catch rates [12]. Where destructive gears have damaged such habitats, fish availability is perceived to have declined [10].

Starting with the biophysical effects, habitats can serve as spawning, feeding, or refuge areas, which may increase the growth of stock, increase the numbers of fish and/or fish weight. The symbiotic interaction between the fish and the habitat may be (1) mutualistic, that is, both species benefit from the presence of the other, (2) commensal, that is, the fish benefit from the presence of the habitat, but the presence of fish neither enhances nor diminishes the habitat, or (3) parasitic, that is, one benefits while the other is harmed.

A habitat can be either essential or facultative. Fish may have different habitat requirements according to life stage and season (e.g., breeding, spawning, nursery, and feeding) [13], and such habitats are essential. The Magnuson Stevens Fishery Act in the US defines essential fish habitat (EFH) as "those waters and substrate necessary for spawning, breeding, feeding, or growth to maturity." Where the habitat is deemed essential, it is assumed that it is obligate for the survival of the fish stock. If habitat is totally destroyed the fish or fisheries dependent upon these habitats would not be sustainable [14]. 
Many species have facultative habitat associations throughout their life [15]. These associations may increase survivorship of individuals and may contribute to wide variations in recruitment, but they are not obligate for the survival of populations [15]. Facultative habitat use can be defined as fish using particular or multiple habitat features as shelters from predators and currents, focal sites for prey capture and for reproduction. Species may use the habitats for many important life processes, but the absence of these habitats does not result in the extinction of the species in question.

Table 1 summarises some of the bioeconomic studies incorporating habitat and classifies them in terms of habitat type, habitat interaction, and management and links the models to those presented in this paper. In the bioeconomic literature biophysical effects of habitat change are shown in the stock growth function. Stock growth depends on both carrying capacity and the intrinsic growth rate. There are studies that have accounted for habitat changes through the carrying capacity (e.g., Barbier and Strand [16]), the intrinsic growth rate (e.g., Kahn [17]), and both carrying capacity and intrinsic growth (e.g., Upton and Sutinen [13]). Barbier and Strand [16] estimate the relationship between shrimp stock growth and their mangrove habitat in Campeche, Mexico. A later study by Barbier et al. [18] applied a dynamic production function to assess the role of mangroves in supporting fisheries in Thailand. Both models consider the habitat to be a breeding ground and nursery for the fish stock. In both papers habitat changes are accounted for in the stock carrying capacity and habitat is essential. Kahn [17] incorporates the effect of terrestrial pollution on the stock growth. A harmful environmental change can impact the growth function by changing either that intrinsic growth rate or the stock carrying capacity. Upton and Sutinen [13] designed a bioeconomic model in which one vessel group's fishing effort impacts on the habitat of their targeted species or the habitat of the targeted species of another vessel group. Habitat enters into both the carrying capacity and the intrinsic growth rate. Anderson [19] developed a simple model to generate approximate estimates of some of the economic benefits that would accrue from seagrass restoration, which serves as a preferred habitat for blue crab. Habitat enters either via the intrinsic growth or the carrying capacity.

There are few bioeconomic studies that try to determine the role of habitat for fish stock growth. Foley et al. [20] consider the impact of reduced cold-water coral habitat on the growth function of redfish. They test for a facultative and an essential relationship. Both carrying capacity and the intrinsic growth of the redfish are modelled as functions of the coral.

Kahui and Armstrong [29] model two habitat fish interactions: (1) the habitat is facultative, or (2) the habitat is essential to the fish species. When the habitat is preferred, the cost of harvest is reduced due to the higher aggregation of fish in the area. This cost effect of habitat can be shown through the catchability coefficient. When habitat is essential, as well as harvest costs being reduced, the growth of the stock increases. Thus, Kahui and Armstrong address not only the uncertainty related to the functional roles of habitat (essential or facultative) but also account for a bioeconomic effect.

Bioeconomic habitat effects are less well described in the literature than the biophysical habitat effects. Bioeconomic habitat effects include habitat influence on catchability, and thus costs, as well as on price of harvest. Habitat type may be an indication of where greater numbers of fish aggregate and thereby increase catchability.

The price of species harvested over particular habitats may also be affected, although not directly by habitat, but indirectly through the market and consumer preferences. Habitat may have an effect on feeding success and growth of commercial species as described by Shephard et al. [6] for plaice in the Celtic Sea. Consumers may be willing to pay more for bigger fish or willing to pay a size-based price. There are many types of ecolables for seafood, such as the Marine Stewardship Council (MSC) and the Nordic Council [30], where consumer preferences with regards to environmental conservation come to play. For instance, fisheries that preserve habitats may obtain a price premium, or habitat destructive harvesting may reduce consumers' willingness to pay for the harvested species. Note that we study ways that habitats enter into fisheries outside of traditional fisheries management control, be they via nature or the market. Clearly, a levy charged to fishers on landings from a certain area or for the use of habitat destructive gear would be equivalent to a price reduction. However, this would be more in line with chosen management, which we consider to be exogenous to the habitat-fishery model.

The bioeconomic effects enter through the harvest function or the profit function. Ellis and Fisher [23] present a standard Cobb-Douglas harvest function which depends on habitat and environmental quality, where environmental quality is fixed. Habitat increases the stock of blue crab and reduces costs. However, stock is not included in the harvest function and harvests depend only on habitat and effort. Freeman [25] adds to the Ellis and Fisher model by considering habitat effects under different management regimes, specifically open access and optimal management. Sathirathai and Barbier [27] apply the Ellis-Fisher-Freeman model to mangroves in Southern Thailand. McConnell and Strand [31] investigate the social returns to commercial fisheries when water quality influences the demand and supply for commercial fish products, and water quality influences both price and costs.

Although there exist reviews on environmental influences in the bioeconomic literature (Knowler [8], Barbier [9]), missing from the literature is a review of how habitat changes affect commercial stocks or the fisheries upon these stocks. There is no discussion of the theoretical foundations of habitat interactions on the bioeconomic parameters: price, catchability, intrinsic growth, or the carrying capacity. In the following we develop the theoretical foundations of the interactions presented in the literature.

\section{The Models}

As mentioned above, we study the habitat effects that are a priori outside of management control, that is, based on 


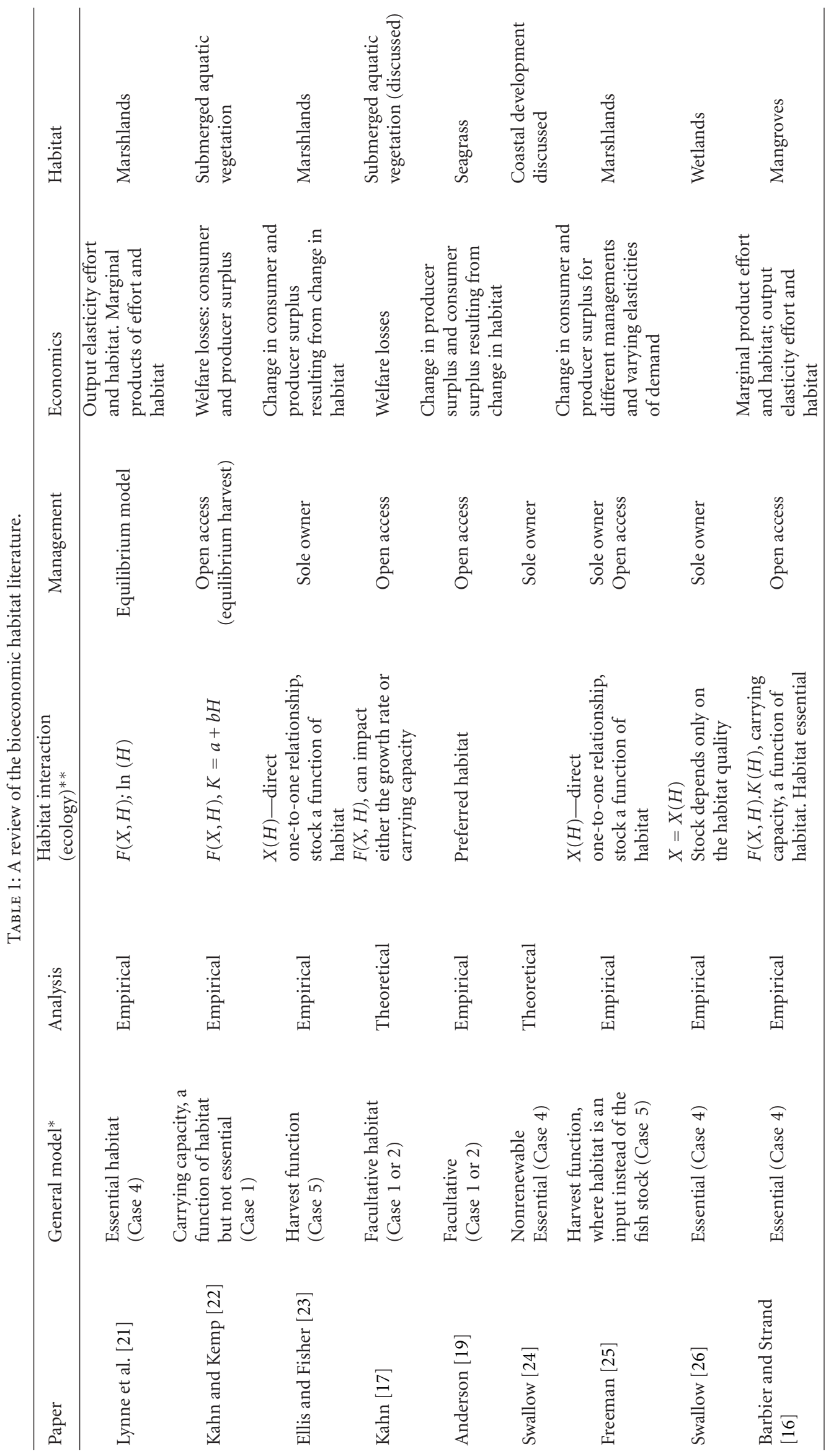




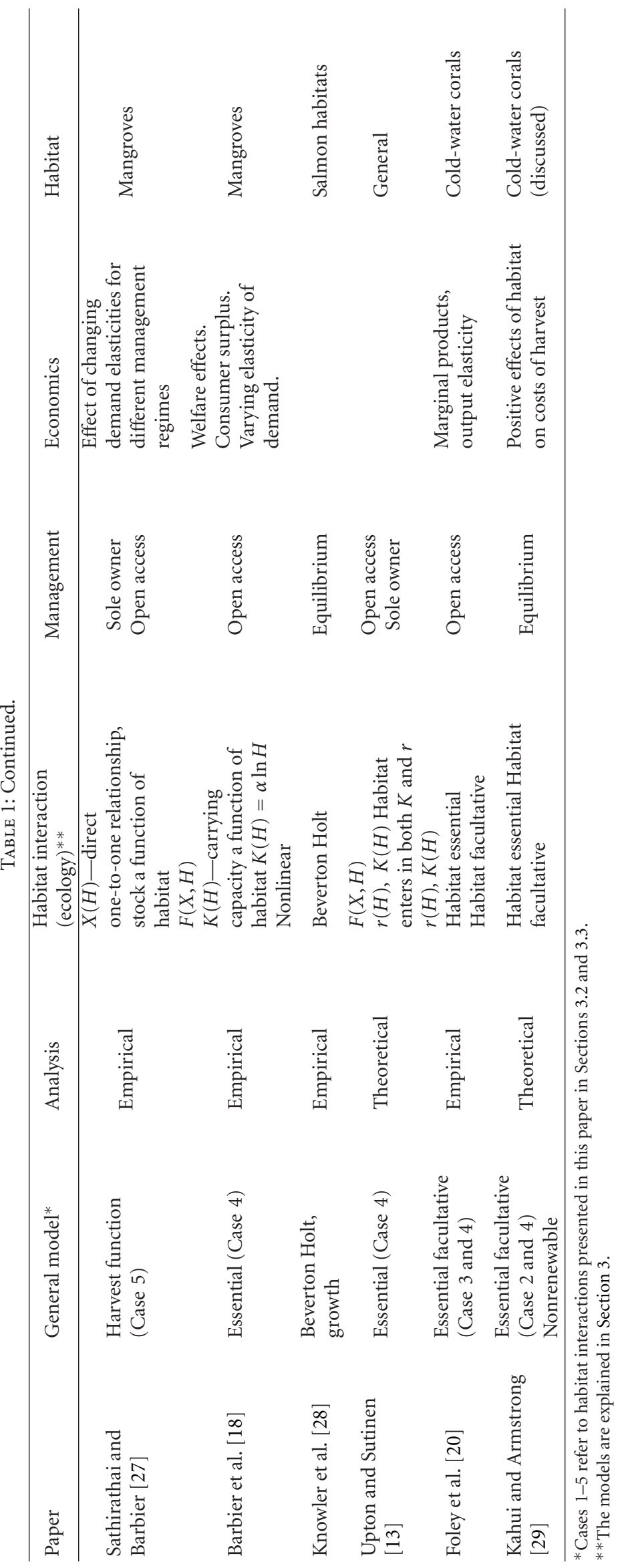


natural interactions or consumer preferences. Hence, the interactions are defined by the model. We then analyse how different management actions affect the fishery, such as open access and maximum economic yield (MEY). The two management options can be considered as the outer limits of management in the dynamic bioeconomic model. By definition, open access is the situation in which a resource is completely uncontrolled: anyone can harvest the resource [32], and effort will enter until all rents are dissipated. In a dynamic setting, this means that the discount rate is infinite. In contrast, management to secure the static MEY seeks to maximise profits and is equivalent to applying a zero discount rate in the dynamic setting.

A general model is first presented in which all habitat interactions are nested. This is followed by a discussion of the influence of habitat improvements on particular parameters within the model.

3.1. General Model. Biophysical effects of fisheries-habitat interactions are shown by their effect on the growth function. We define a general growth function, which nests the different fisheries-habitat interactions as follows:

$$
F(X, H)=r(H) X\left(1-\frac{X}{K(H)}\right) .
$$

This is the logistic growth function modified to allow for habitat, where $X$ is the biomass of fish stock and $H$ is the habitat. $K(H)$ is the environmental carrying capacity (where $K(H) \geq X \geq 0$ ), and $r(H)>0$ is the intrinsic growth rate, both functions of the habitat.

Studying linear forms for intrinsic growth $r(H)$ and carrying capacity $K(H)$ in (1) allows the description of both essential and facultative habitat-fish interactions as

$$
\begin{aligned}
& r(H)=a+b H, \\
& K(H)=f+g H .
\end{aligned}
$$

According to the equations in (2), a habitat is essential if either $a=0$ and/or $f=0$ (because $r(0)=0$ and/or $K(0)=0)$. This is the case in the Barbier and Strand [16] model, where $a=0$. Barbier et al. [18] also describe an essential fish-habitat interaction, where $a=f=0$, but the model assumes a nonlinear functional form.

If, however, $\{a, f\}>0$ and $\{b, g\} \geq 0$, we have a case of facultative or preferred habitat, where growth may remain positive despite a zero habitat (if $a$ equals the intrinsic growth rate, $\tilde{r}$, and $f$ equals the carrying capacity, $\widetilde{K}$, and $g=b \tilde{K} / \tilde{r}$, $b$ is the predation coefficient of the predator upon the prey in the standard predator-prey model).

Bioeconomic effects can be shown in the harvest function or the profit function. Scientific research reports higher density of fish in habitat-rich areas, leading to increased catchability for fishers and reduced costs. To reflect this, the standard Schaefer harvest function can be adjusted to allow for habitat:

$$
h=h(H, E, X)=q(H) E X,
$$

where $E$ is fishing effort and $q(H)$ is the catchability coefficient which is a function of habitat, $H$.
If the stock is subjected to harvest, the net growth in the stock is the difference between the natural growth rate and harvest according to

$$
\frac{d X}{d t}=F(X, H)-h(E, X, H)
$$

Profits from the fishery can be described as

$$
\pi=\mathrm{TR}-\mathrm{TC}
$$

where TR is total revenue and TC is total cost. The equilibrium profits from the fishery can be described both as a function of stock size and effort.

When equilibrium profits are described as a function of stock size (see left-hand side of Figures 3 and 4), TR is the product of price and equilibrium harvest and TC is the product of unit cost of harvest and equilibrium harvest. The unit cost of harvest decreases with rising catchability and stock size.

When equilibrium profits are described as a function of effort (see right-hand side of Figures 3 and 4), TR is the product of price and equilibrium harvest and TC is the product of effort and the unit cost of effort, where the unit cost of effort is assumed constant.

We will study the effect of habitat on TR, TC, and equilibrium levels of stock and effort under open access and MEY, for the different types of habitat interactions presented in the following.

There can also be an indirect relationship between price and habitat, as mentioned above, which can be accounted for in the profit function. Price is affected by the perceived sustainability of the fishery, resulting in a unit harvest price premium.

In what follows, each individual interaction is outlined. Although the relationship between habitat and each of the parameters may be linear or nonlinear, for ease of exposition a linear relationship is assumed throughout.

3.2. Biophysical Effects. Facultative and essential habitat models are presented in this section. By definition (see equation (2)), a habitat may affect the growth of a fish stock via

(a) the carrying capacity,

(b) the intrinsic growth rate,

(c) or both the carrying capacity and the intrinsic growth.

The following provides more detailed descriptions of biophysical effects.

3.2.1. Case 1: Carrying Capacity. The growth function is adjusted to allow the habitat to influence the stock carrying capacity. The carrying capacity depends on the natural environment of the stock, such as size of the habitat. Habitat improvements could increase the carrying capacity of the stock due to such functions as increased nutrient supply, nursery grounds, and refuge from predators. For $b=0$ and 


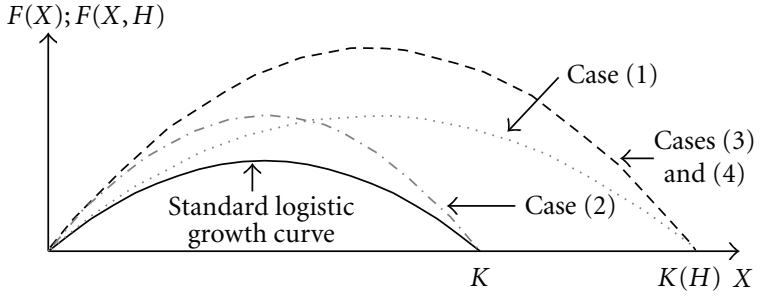

Figure 2: Habitat effects on the logistic growth curve. The black solid line shows the standard logistic growth curve, while the dashed black line shows the positive effect of habitat on both the carrying capacity and intrinsic growth rate (Cases (3) and (4)). The grey lines show the influence of habitat on intrinsic growth (Case (2)) and carrying capacity individually (Case (1)).

$\{a, f, g\}>0$ in (2), the intrinsic growth rate is independent of habitat and (1) can be restated as

$$
\begin{gathered}
F(X, H)=a X\left(1-\frac{X}{(f+g H)}\right), \\
F_{X}>0, \quad F_{H}>0, \quad F(X, 0)>0 \quad \text { for } X>0,
\end{gathered}
$$

where $(f+g H)$ is the modified stock carrying capacity, with $f$ representing the general carrying capacity of the stock and $g$ the sensitivity coefficient by which habitat positively influences the carrying capacity. Figure 2 illustrates the effect of introducing habitat into the growth function when carrying capacity is a function of habitat. This case and the following (case 2) are similar to those of Mikkelsen[33], where aquaculture-fisheries interactions are analysed and it is assumed that aquaculture imposes an externality on the wild fish stock which can enter the growth function through either the carrying capacity or the intrinsic growth rate.

3.2.2. Case 2: Intrinsic Growth. Shephard et al. [6] found evidence that changes in habitat may have affected the growth of plaice through the intrinsic growth rate. For $g=0$ and $\{a, f, g\}>0$ in (2), carrying capacity is independent of habitat. The availability of habitat may simply provide preferred spawning grounds and refuge from predators. The growth function now becomes

$$
F(X, H)=(a+b H) X\left(1-\frac{X}{f}\right), \quad F_{H}>0 .
$$

Here $a$ represents the standard intrinsic growth when $H=$ 0 , and $b$ is the coefficient of sensitivity by which habitat $H$ influences the stock growth. An increase in the intrinsic growth is illustrated in Figure 2, where the slope of the growth function becomes steeper.

3.2.3. Case 3: Carrying Capacity and Intrinsic Growth. It is also possible that both carrying capacity and the intrinsic growth rate are increasing functions of habitat in the facultative model as shown by Foley et al. [20]. For $\{a, b, f, g\}>0$, the growth function becomes

$$
F(X, H)=(a+b H) X\left(1-\frac{X}{(f+g H)}\right), \quad F_{H}>0 .
$$

The impact of habitat on both the carrying capacity and the intrinsic growth is illustrated in Figure 2.

3.2.4. Case 4: Essential Habitat. For $a=f=0$ in (2) (for the habitat to be essential, it is only necessary for either $a=0$ or $f=0$, but it also holds for both $a$ and $f$ being zero as presented here), a proportional relationship exists between the habitat and the intrinsic growth, as well as between habitat and the carrying capacity when $\{b, g\}>0$. The habitat is essential; it is obligate for the growth and survival of the stock. The growth function becomes

$$
\frac{d X}{d t}=F(X, H)=(b H) X\left(1-\frac{X}{g H}\right), \quad F_{H}>0,
$$

where $F(X, 0)=0$. This growth function has been employed by Upton and Sutinen [13], who also modified intrinsic growth and carrying capacity separately. They found that in each case the results were similar. Barbier and Strand [16] and Foley et al. [20] also present habitat as essential for the growth of the fish stock. The effect of an essential habitat on the growth function is similar to Case (3) and results in an outward shift of the growth curve (see Figure 1).

This section has explored the various ways habitat can affect the growth function of a fish species, and we show how these effects can be nested in an overarching function such as (1). These effects, as presented in Figure 2, translate directly to total revenues via the equilibrium harvest function (see Figure 6) and also into the total costs as a function of stock size.

\subsection{Bioeconomic Effects}

3.3.1. Case 5: Habitat and Catchability Coefficient. Using equation (3) it is assumed that habitat influences the catchability coefficient. The catchability, $q$, is a linear function of habitat, $H$. The model is similar to what is presented in Mikkelsen [33] where the catchability coefficient is adjusted to allow for a potential impact of aquaculture on the fishery.

In this case, it is assumed that habitat positively influences the catchability coefficient. For instance, higher densities of fish may be expected to congregate in the habitat area, and the concentration of targeted species will add to the catchability. However, the effect could also be negative and increase harvesting costs by making grounds more difficult to fish, snag nets and require more robust gears. Habitats such as cold water corals, for example, could either enhance or detract from the catchability coefficient.

The growth of the stock is now assumed to be independent of habitat; the intrinsic growth rate and carrying capacity in (1) are reduced to constants. The effect of habitat on TR, TC, and equilibrium solutions under open access and 


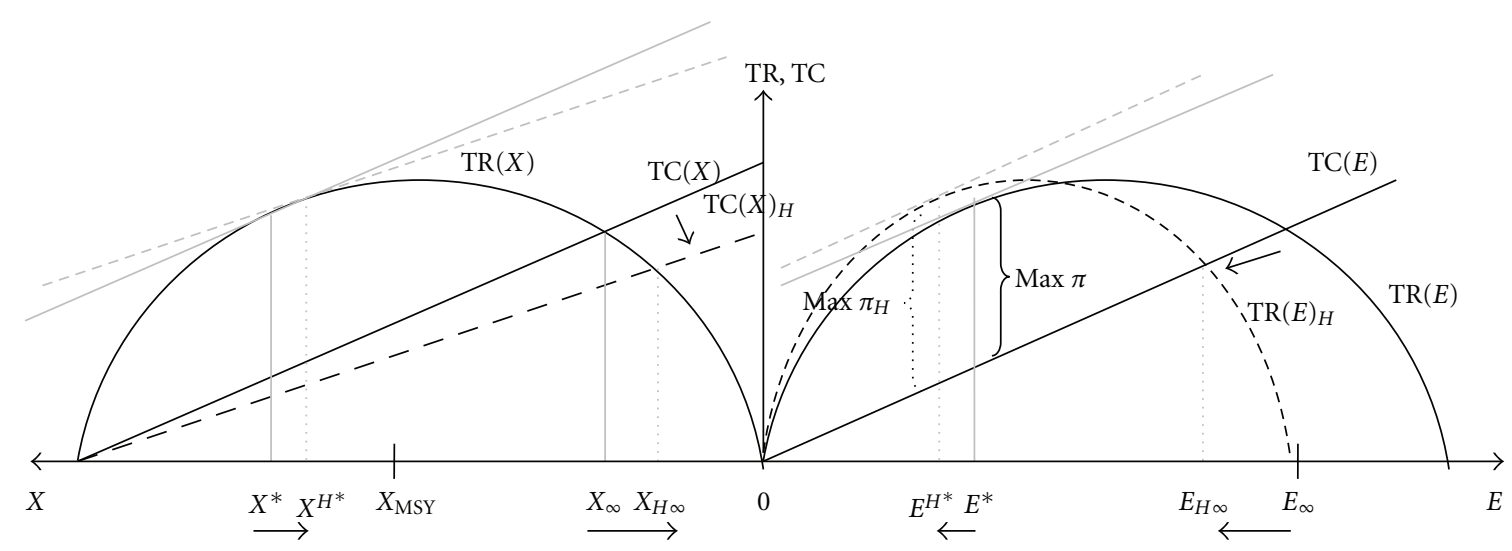

Note: low costs, $X_{\infty}<X_{\mathrm{MSY}}$

FIGURE 3: The effect of habitat via the catchability on TR, TC, and equilibrium solutions under open access and maximum economic yield (MEY) when unit costs of effort are low.

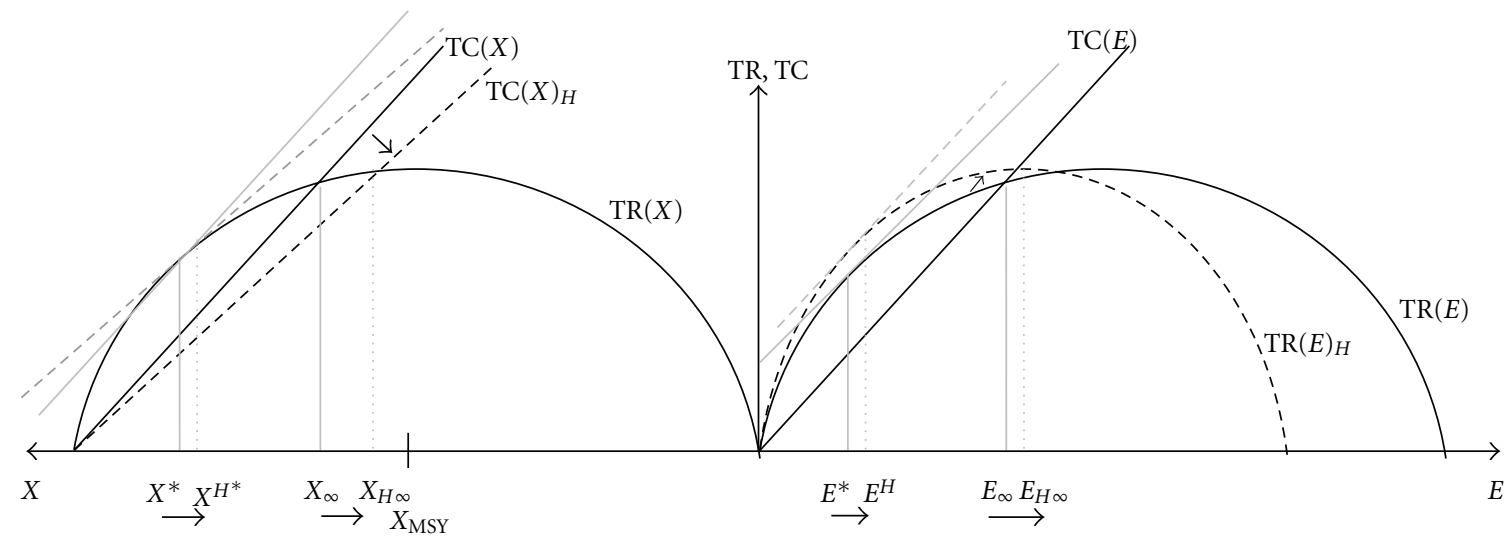

Note: high costs, $X_{\infty}>X_{\mathrm{MSY}}$

FIGURE 4: The effect of habitat via the catchability on TR, TC, and equilibrium solutions under open access and maximum economic yield (MEY) when unit costs of effort are high.

MEY is illustrated in Figures 3 and 4. For both open access and MEY, the effects of habitat depend on whether high or low fishing costs are incurred, that is, whether $X_{\infty}>X_{\mathrm{MSY}}$ or $X_{\infty}<X_{\mathrm{MSY}}$, where $X_{\infty}$ is the open access stock and $X_{\mathrm{MSY}}$ is the stock at maximum economic yield. Assuming $X_{\infty}<X_{\mathrm{MSY}}$ as shown in Figure 3, an increased habitat increases total revenue and shifts the total revenue curve as a function of effort to the left thus reducing the total costs. The opposite is illustrated in Figure 4 , where $X_{\infty}>X_{\mathrm{MSY}}$. Total costs are now high. The effect of a decline in habitat on the catchability coefficient is discussed in Section 4 on comparative statics.

3.3.2. Case 6: Habitat and Price. Ecolabels may be attached to species caught in a sustainable manner or with gears that are protective of the marine environment in which the species survives. The price is not directly related to the habitat but to the fishing methods used over the habitats. However, it may be inferred that the use of less damaging gears over certain habitats may yield a price premium; $p_{\text {premium }}=$
$p+\hat{p}_{H}$ where $\hat{p}_{H}$ represents a price premium that consumers are willing to pay when habitat sensitive gears are used in the fishery, $\hat{p}_{H} \geq 0$. If the gear is destructive, there is no premium, $\hat{p}_{H}=0$. An example is dolphin friendly tuna, where the purpose of ecolabeling tuna is to protect dolphins from mortality or harm as a result of harvesting tuna. Gudmundsson and Wessells [30] suggest that a price premium will most likely be constant. As shown in Figure 5, a price premium will shift the total revenue curve up. This will result in an increase in effort and yield for both open access and MEY and stock levels when there is an increased willingness to pay.

\section{Comparative Static Analysis}

In the presentation of the biophysical and the bioeconomic models, the discussion is based on how increased or improved habitat changes stock, growth, effort, and harvest compared to the standard model. However, the concern related to habitat is that of habitat loss in size and/or quality 


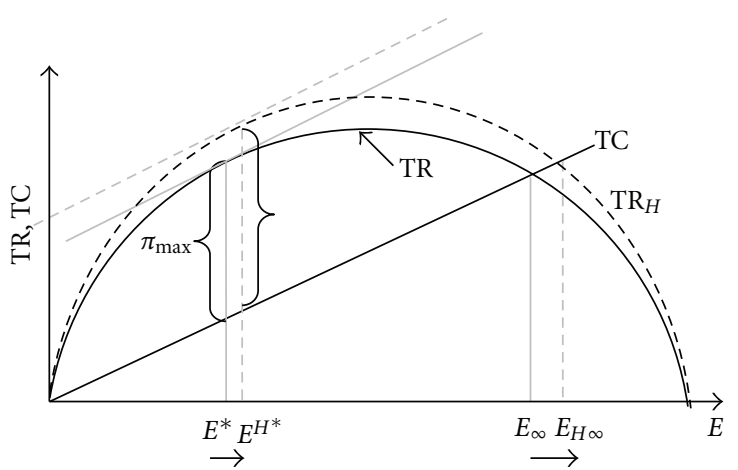

FIGURE 5: Habitat effect on price, and thereby total revenues, giving equilibrium effort for the two management options, open access (indicated by $\infty$ ) and MEY (indicated by ${ }^{*}$ ).

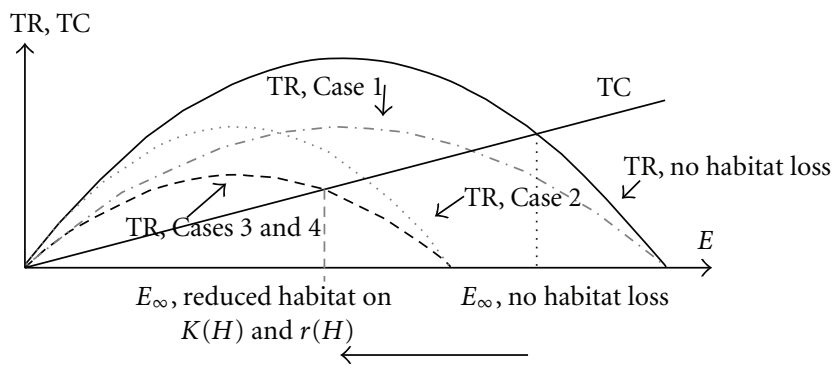

Figure 6: Habitat effects on open access effort for each of the biophysical models. Reduced or damaged habitat results in lower effort.

TABle 2: Effects of habitat loss on biophysical models, price, and catchability.

\begin{tabular}{lcccc}
\hline & & Stock & Effort & Harvest \\
\hline Biophysical models & OA & 0 & - & - \\
(Cases 1-4) & MEY & $-*$ & - & - \\
Catchability (Case 5) & OA & + & + & + \\
$\left(X_{\infty}<X_{\text {MSY }}\right)$ & MEY & + & + & - \\
Catchability (Case 5) & OA & + & - & - \\
$\left(X_{\infty}>X_{\text {MSY }}\right)$ & MEY & + & - & - \\
Price (Case 6) & OA & + & - & - \\
& MEY & + & - & - \\
\hline
\end{tabular}

* An exception to this is Case 2 in which growth is a function of habitat, $r(H)$, where the steady-state MEY stock is independent of habitat.

as mentioned in the introduction. Table 2 summarises the effect of habitat degradation given management conditions being open access and MEY.

For all of the biophysical models, effort and yield will decrease with habitat when there is open access. Habitat will however have no effect on the open access stock level, as it is only a function of the economic and technological parameters. At the other end of the management scale, MEY, all equilibrium conditions decline with a degraded habitat, with the exception of Case 2 which alters the intrinsic growth only; in this case the steady-state stock is independent of habitat. Reduced habitat in the biophysical model will result in smaller steady-state stock, effort, and yield. Overall maximum profits decrease in all models when habitat is degraded. Some of these effects are illustrated in Figure 6.

The change in the catchability coefficient is influenced by habitat degradation. The results of this situation depend in part on whether initial fishing costs are high or low, as discussed in the previous section. Assuming $X_{\infty}<X_{\mathrm{MSY}}$ as shown in Figure 3, damaged habitat increases total costs as a function of stock size. In the case of open access, equilibrium stock, effort, and harvest are increased. For maximum economic yield, a reduced habitat increases equilibrium stock and effort, but harvest and profits fall. High total costs are illustrated in Figure 4, where $X_{\infty}>X_{\text {MSY }}$. With the reduction of habitat open access equilibrium stock increases while effort and harvest decrease. For maximum economic yield, equilibrium stock increases and maximum profits, effort, and harvest fall. Finally Table 2 shows the effect of decreasing willingness to pay for species harvested when habitat declines. The equilibrium stocks will increase, and equilibrium harvest and effort will be reduced for both MEY and open access. MEY profits will fall.

\section{Conclusions}

Although there is a bioeconomic literature on habitatfish interactions, there appears to be no study synthesising how habitat can feed into the standard Gordon-Schaefer bioeconomic model. This paper has identified, reviewed, and set out the theoretic foundations for habitat linkages in a bioeconomic setting. It has categorized and sorted a number of models from the literature on habitat-fish interactions and showed how they can be nested into the standard bioeconomic model. Table 1 summarises this literature under headings of habitat, model type, and management. For ease of exposition, the relationship between fish and the habitat is presented as linear; however, this could be expanded to consider nonlinear relationships within the models.

Habitat can enter the bioeconomic model in a number of ways through the growth function, profit function, or the harvest function. Two specific biophysical interactions are considered between the habitat and the growth of the fish stock, where habitat is either essential or facultative to the fish. If the habitat is facultative, it can affect either the carrying capacity or the intrinsic growth rate or both. When the habitat is essential for the survival of the stock, it is assumed that it affects both carrying capacity and growth.

Loss of habitat may result in fish becoming more dispersed, thus increasing harvesting costs or reducing catchability or even the market price of species. These interactions of habitat on fisheries have been presented as bioeconomic effects and can be modelled as affecting the catchability coefficient of the harvest function. It is also shown that a price premium may be earned for fish harvested using nondestructive gears, thus increasing price. The effect of habitat loss on the fishery is analysed at open access and maximum economic yield levels which can be considered the outer limits of management in the dynamic bioeconomic model.

For the future, at least three avenues of research are worth exploring. First, in this paper the interaction of habitat 
within the bioeconomic model is the focus. We do not look at the habitat side or define the habitat. There is no habitat growth function. Future work should define habitat and consider the multispecies interaction between habitat and the fish. This will allow for the acceptable annual damage to habitats due to their growth and regeneration to be calculated and will also lend further discussion on the effects of fishing on habitat and the associated economic consequences. Second, in this review individual connections have been analysed; however, it is more likely that there will be combinations between biophysical and bioeconomic interactions. The review could be expanded with an application of data related to a specific fishery with habitat connections to estimate which model or combinations fit best. Third, different management options such as marine protected areas or restricted access with regard to habitat fisheries interactions should be considered.

\section{Acronyms}

EFH: Essential fish habitat

OA: Open access

MEY: Maximum economic yield

MSC: Marine stewardship council

SAV: Submerged aquatic vegetation

TC: Total cost

TR: Total revenue

\section{Acknowledgments}

This study has been carried out with support of the Commission of the European Communities, specifically Seventh Framework Programmes (FP7/2007-2013) under Grant Agreement no. 213144, CoralFISH, and the HERMIONE project, Grant Agreement no. 226354. It does not necessarily reflect the Commission's views or anticipate future policy in this area.

\section{References}

[1] L. W. Botsford, J. C. Castilla, and C. H. Peterson, "The management of fisheries and marine ecosystems," Science, vol. 277, no. 5325, pp. 509-515, 1997.

[2] J. B. Lindholm, P. J. Auster, M. Ruth, and L. Kaufman, "Modeling the effects of fishing and implications for the design of marine protected areas: juvenile fish responses to variations in seafloor habitat," Conservation Biology, vol. 15, no. 2, pp. 424437, 2001.

[3] L. Watling and E. A. Norse, "Disturbance of the seabed by mobile fishing gear: a comparison to forest clearcutting," Conservation Biology, vol. 12, no. 6, pp. 1180-1197, 1998.

[4] E. B. Barbier, E. W. Koch, B. R. Silliman et al., "Coastal ecosystem-based management with nonlinear ecological functions and values," Science, vol. 319, no. 5861, pp. 321-323, 2008.

[5] C. W. Armstrong and J. Falk-Petersen, "Habitat-fisheries interactions: a missing link?" ICES Journal of Marine Science, vol. 65 , no. 6, pp. 817-821, 2008.

[6] S. Shephard, D. Brophy, and D. G. Reid, "Can bottom trawling indirectly diminish carrying capacity in a marine ecosystem?" Marine Biology, vol. 157, no. 11, pp. 2375-2381, 2010.
[7] J. G. Hiddink, A. D. Rijnsdorp, and G. Piet, "Can bottom trawling disturbance increase food production for a commercial fish species?" Canadian Journal of Fisheries and Aquatic Sciences, vol. 65, no. 7, pp. 1393-1401, 2008.

[8] D. Knowler, "A review of selected bioeconomic models with environmental influences in fisheries," Journal of Bioeconomics, vol. 4, no. 2, pp. 163-181, 2002.

[9] E. B. Barbier, "Valuing the environment as input: review of applications to mangrove-fishery linkages," Ecological Economics, vol. 35, no. 1, pp. 47-61, 2000.

[10] C. W. Armstrong and S. van den Hove, "The formation of policy for protection of cold-water coral off the coast of Norway," Marine Policy, vol. 32, no. 1, pp. 66-73, 2008.

[11] M. J. Costello, M. McCrea, A. Freiwald et al., "Role of coldwater Lophelia pertusa coral reefs as fish habitat in the NE Atlantic," in Cold-Water Corals and Ecosystems, A. Freiwald and J. M. Roberts, Eds., pp. 771-805, Springer, Berlin, Germany, 2005.

[12] K. A. Puglise, R. J. Brock, and J. J. McDonough, "Identifying critical information needs and developing institutional partnerships to further the understanding of Atlantic deepsea coral ecosystems," in Cold-Water Corals and Ecosystems, A. Freiwald and J. M. Roberts, Eds., pp. 1129-1140, Springer, Berlin, Germany, 2005.

[13] H. F. Upton and J. G. Sutinen, When Do Marine Protected Areas Pay? An Analysis of Stylized Fisheries, University of Rhode Island, 2003.

[14] P. J. Auster, "A conceptual model of the impacts of fishing gear on the integrity of fish habitats," Conservation Biology, vol. 12, no. 6, pp. 1198-1203, 1998.

[15] P. J. Auster and R. W. Langton, "The effects of fishing on fish habitat," American Fisheries Society Symposium, vol. 22, pp. 150-187, 1999.

[16] E. B. Barbier and I. Strand, "Valuing mangrove-fishery linkages. A case study of Campeche, Mexico," Environmental and Resource Economics, vol. 12, no. 2, pp. 151-166, 1998.

[17] J. R. Kahn, "Measuring the economic damages associated with environmental influences in fisheries," Marine Resource Economics, vol. 4, p. 1933, 1987.

[18] E. B. Barbier, I. Strand, and S. Sathirathai, "Do open access conditions affect the valuation of an externality? Estimating the welfare effects of mangrove-fishery linkages in Thailand," Environmental and Resource Economics, vol. 21, no. 4, pp. 343$367,2002$.

[19] E. E. Anderson, "Economic benefits of habitat restoration: seagrass and the Virginia hard-shell blue crab fishery," North American Journal of Fisheries Management, vol. 9, no. 2, pp. 140-149, 1989.

[20] N. S. Foley, V. Kahui, C. W. Armstrong, and T. M. van Rensburg, "Estimating linkages between redfish and cold water coral on the Norwegian Coast," Marine Resource Economics, vol. 25, no. 1, pp. 105-120, 2010.

[21] G. D. Lynne, P. Conroy, and F. J. Prochaska, "Economic valuation of marsh areas for marine production processes," Journal of Environmental Economics and Management, vol. 8, no. 2, pp. 175-186, 1981.

[22] J. R. Kahn and W. M. Kemp, "Economic losses associated with the degradation of an ecosystem: the case of submerged aquatic vegetation in Chesapeake Bay," Journal of Environmental Economics and Management, vol. 12, no. 3, pp. 246-263, 1985.

[23] G. M. Ellis and A. C. Fisher, "Valuing the environment as input," Journal of Environmental Management, vol. 25, no. 2, pp. 149-156, 1987. 
[24] S. K. Swallow, "Depletion of the environmental basis for renewable resources: the economics of interdependent renewable and nonrenewable resources," Journal of Environmental Economics and Management, vol. 19, no. 3, pp. 281-296, 1990.

[25] A. M. Freeman, "Valuing environmental resources under alternative management regimes," Ecological Economics, vol. 3, no. 3, pp. 247-256, 1991.

[26] S. K. Swallow, "Renewable and nonrenewable resource theory applied to coatal agriculture, forest, wetland, and fishery linkages," Marine Resource Economics, vol. 9, no. 4, pp. 291-310, 1994.

[27] S. Sathirathai and E. B. Barbier, "Valuing mangrove conservation in Southern Thailand," Contemporary Economic Policy, vol. 19, no. 2, pp. 109-122, 2001.

[28] D. J. Knowler, B. W. MacGregor, M. J. Bradford, and R. M. Peterman, "Valuing freshwater salmon habitat on the west coast of Canada," Journal of Environmental Management, vol. 69, no. 3, pp. 261-273, 2003.

[29] V. Kahui and C. Armstrong, Fishing on Cold Water Coral Reefs: A Bioeconomic Model of Habitat-Fishery Connections, University of Tromso, 2010.

[30] E. Gudmundsson and C. R. Wessells, "Ecolabeling seafood for sustainable production: implications for fisheries management," Marine Resource Economics, vol. 15, no. 2, pp. 97-113, 2000.

[31] K. E. McConnell and I. E. Strand, "Benefits from commercial fisheries when demand and supply depend on water quality," Journal of Environmental Economics and Management, vol. 17, no. 3, pp. 284-292, 1989.

[32] C. W. Clark, Mathematical Bioeconomics. The Optimal Management of Renewable Resources, John Wiley \& Sons, Hoboken, NJ, USA, 2nd edition, 1990.

[33] E. Mikkelsen, "Aquaculture-fisheries interactions," Marine Resource Economics, vol. 22, pp. 287-303, 2007. 

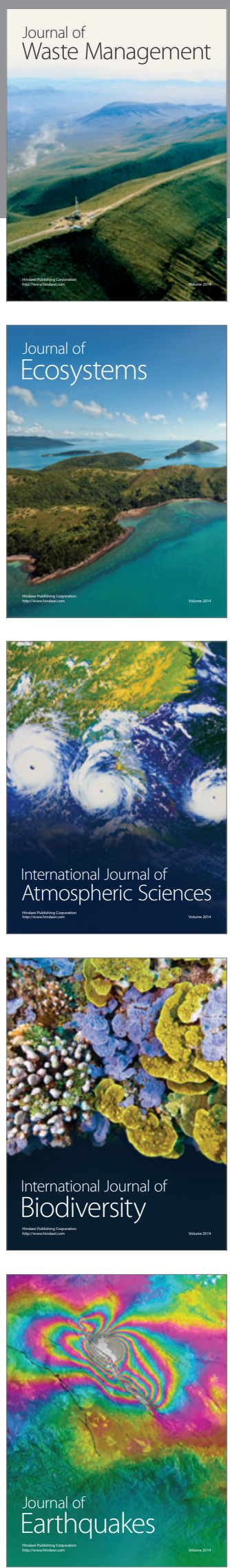
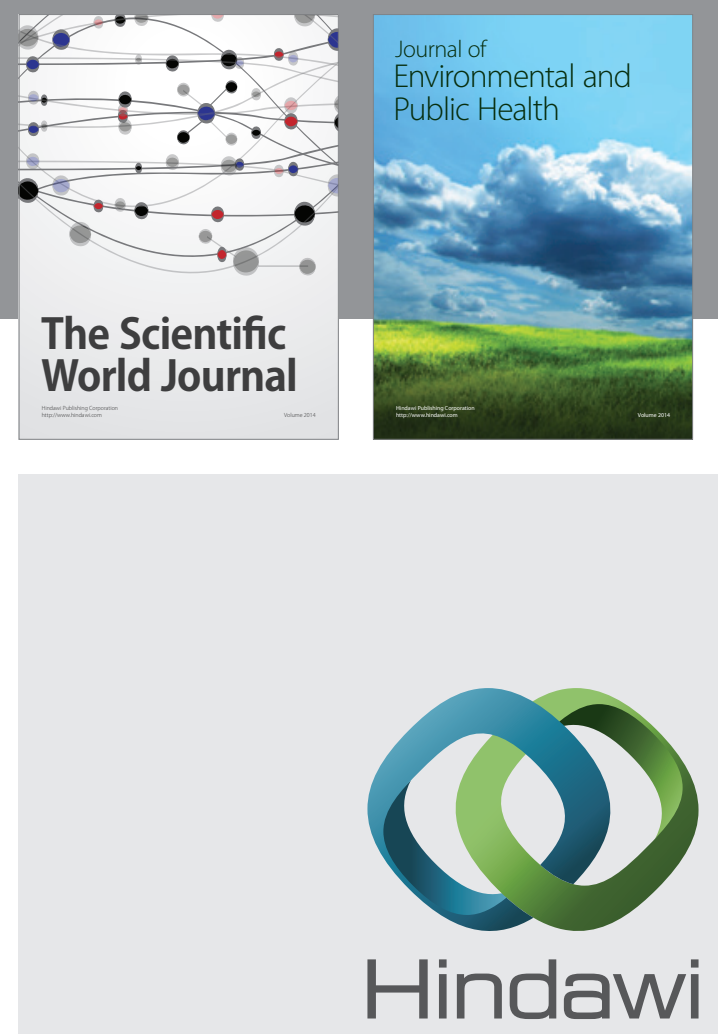

Submit your manuscripts at

http://www.hindawi.com
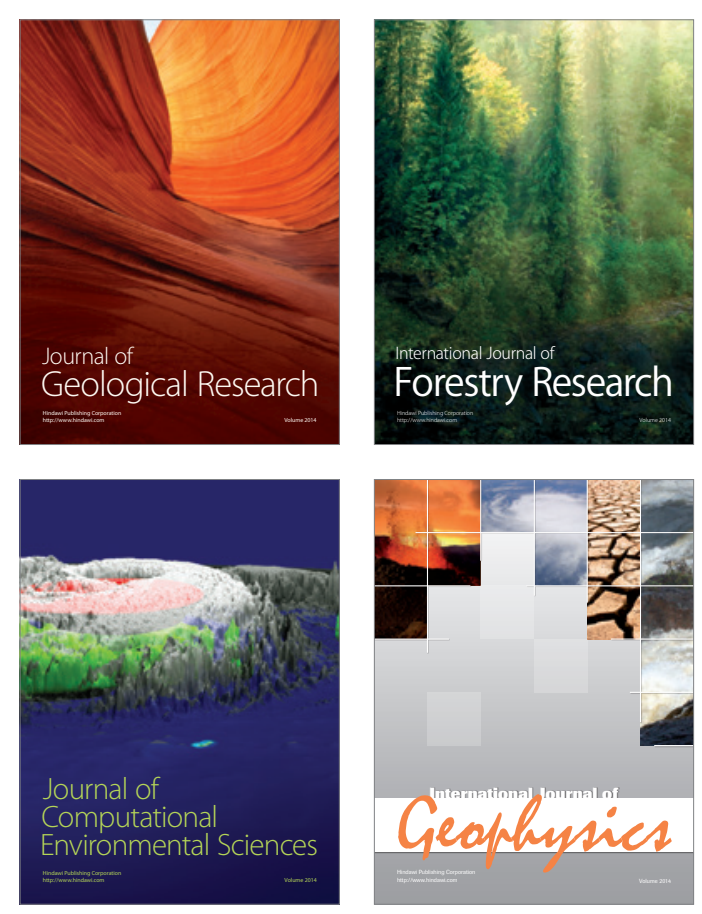
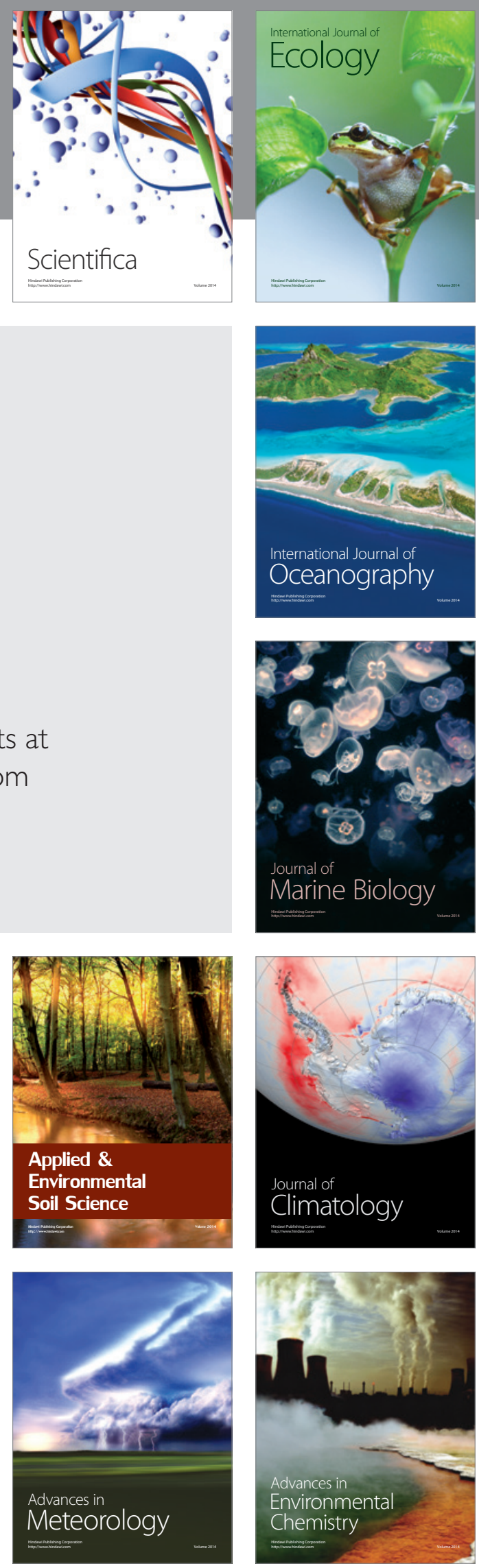